Check for updates

Cite this: RSC Adv., 2019, 9, 5844

\title{
Catalytic pyrolysis of plastic waste for the production of liquid fuels for engines $\dagger$
}

\author{
Supattra Budsaereechai, ${ }^{a}$ Andrew J. Hunt $\mathbb{D D}^{\mathrm{b}}$ and Yuvarat Ngernyen ${ }^{\star a}$
}

Catalytic pyrolysis of waste plastics using low cost binder-free pelletized bentonite clay has been investigated to yield pyrolysis oils as drop-in replacements for commercial liquid fuels such as diesel and gasohol 91. Pyrolysis of four waste plastics, polystyrene, polypropylene, low density polyethylene and high density polyethylene, was achieved at a bench scale (1 $\mathrm{kg}$ per batch) to produce useful fuel products. Importantly, the addition of binder-free bentonite clay pellets successfully yielded liquid based fuels with increased calorific values and lower viscosity for all plastic wastes. This larger scale pyrolysis study demonstrated that use of a catalyst in powder form can lead to significant pressure drops in the catalyst column, thus slowing the process (more than 1 hour). Importantly, the use of catalyst pellets eliminated the pressure drop and reduced pyrolysis processing time to only 10 minutes for $1 \mathrm{~kg}$ of plastic waste. The pyrolysis oil composition from polystyrene consists of $95 \%$ aromatic hydrocarbons, while in contrast, those from polypropylene, low density polyethylene and high density polyethylene, were dominated by aliphatic hydrocarbons, as confirmed by GC-MS. FTIR analysis demonstrated that low density polyethylene and high density polyethylene oils had functional groups that were consistent with those of commercial diesel ( $96 \%$ similarity match). In contrast, pyrolysis-oils from polystyrene demonstrated chemical and physical properties similar to those of gasohol 91 . In both cases no wax formation was observed when using the bentonite clay pellets as a catalyst in the pyrolysis process, which was attributed to the high acidity of the bentonite catalyst (low $\mathrm{SiO}_{2}: \mathrm{Al}_{2} \mathrm{O}_{3}$ ratio), thus making it more active in cracking waxes compared to the less acidic heterogeneous catalysts reported in the literature. Pyrolysis-oil from the catalytic treatment of polystyrene resulted in greater engine power, comparable engine temperature, and lower carbon monoxide $(\mathrm{CO})$ and carbon dioxide $\left(\mathrm{CO}_{2}\right)$ emissions, as compared to those of uncatalysed oils and commercial fuel in a gasoline engine. Pyrolysis-oils from all other polymers demonstrated comparable performance to diesel in engine power tests. The application of inexpensive and widely available bentonite clay in pyrolysis could significantly aid in repurposing plastic wastes.

rsc.li/rsc-advances

\section{Introduction}

The consumption of plastics is increasing worldwide and thus plastic waste is now one of the major components of municipal solid waste. The challenge of dealing with plastic waste has been managed by a number of different methods depending on local regulations and what is socially acceptable, including recycling, reuse, disposal at landfill and conversion to energy by pyrolysis. ${ }^{1}$ Pyrolysis is the sustainable management of plastic waste along with production of liquid oil as a source of energy and solid char and gases as value-added products. ${ }^{2}$ This process

${ }^{a}$ Department of Chemical Engineering, Faculty of Engineering, Khon Kaen University, Khon Kaen, 40002, Thailand. E-mail: nyuvarat@kku.ac.th

${ }^{b}$ Materials Chemistry Research Center, Department of Chemistry, Center of Excellence for Innovation in Chemistry, Faculty of Science, Khon Kaen University, Khon Kaen, 40002, Thailand

$\dagger$ Electronic supplementary information (ESI) available. See DOI: 10.1039/c8ra10058f involves thermal degradation of complex molecules or large chain hydrocarbons into smaller molecules or shorter chain hydrocarbons. Catalysts are widely used in the pyrolysis process to optimize product distribution and increase the product selectivity. Catalysts have also been employed in the upgrading of pyrolysis products to improve the hydrocarbon distribution and yield similar properties to the conventional fuels such as diesel and gasoline. ${ }^{3}$

Over the past two decades, a large number of results on catalytic pyrolysis process for plastic have been reported. ${ }^{4-14} \mathrm{~A}$ wide range of catalysts such as $\mathrm{ZnO},{ }^{4} \mathrm{MgO},{ }^{4} \mathrm{CaCO}_{3},{ }^{5} \mathrm{CaC}_{2},{ }^{4}$ $\mathrm{SiO}_{2},{ }^{4} \quad \mathrm{Al}_{2} \mathrm{O}_{3},{ }^{4} \quad \mathrm{SiO}_{2}-\mathrm{Al}_{2} \mathrm{O}_{3},{ }^{4}{ }^{2} \mathrm{ZSM}-5$ zeolite, ${ }^{6-8}$ kaolin,, ${ }^{9,10}$ red mud, ${ }^{8,11} \mathrm{CuCO}_{3},{ }^{12}$ and $\mathrm{FCC},{ }^{13,14}$ have been used. The present study attempts to utilise bentonite clay as an inexpensive and widely abundant material as a catalyst in the pyrolysis of waste plastic. Bentonite has been used in a limited number of studies for the pyrolysis of plastic including the pyrolysis of HDPE, ${ }^{\mathbf{1 5}}$ PP, ${ }^{16}$ LLDPE $^{16}$ and mixed plastic wastes. ${ }^{17}$ This initial proof of 
principle studies demonstrated that bentonite could be a suitable catalyst in pyrolysis process of plastics. ${ }^{16,18,19}$ Typically such catalysts have been utilised in a powder form which leads to a pressure drop that occur in catalyst column and further problems with the process.

The vast majority of these studies have only investigated the pyrolysis plastics on a lab scale (5-200 g). ${ }^{\mathbf{4 , 8 , 9 , 1 1 , 2 0 - 2 2}}$ There are few literature examples that study pyrolysis systems on a larger scale. For example, Miandad et al. examine the effect of different plastic waste types, PS, PE, PP and PET, by using $1 \mathrm{~kg}$ of sample in pyrolysis reactor. ${ }^{23}$ Rehan et al. studied thermal and catalytic pyrolysis of $1 \mathrm{~kg}$ PS plastic waste by using a small pilot scale pyrolysis reactor. ${ }^{24}$ Such studies are key for understanding determining what parameters are important for scale up.

Herein, this work aims to investigate thermal and catalytic pyrolysis of plastic wastes, PS, PP, LDPE and HDPE, in bench scale reactor (maximum capacity $5 \mathrm{~kg}$ ) using bentonite catalysts and compare the properties of resulting oils with commercial fuels, diesel and gasohol 91. This current study uses a bench scale reactor ( $1 \mathrm{~kg}$ per batch) and importantly the information gathered is transferable to a real production scale situation, and can be used for further scale up. Importantly, this current study demonstrates that the utilization of binder-free compressed catalyst pellets at scale can eliminate the pressure drop that can typically occur in catalyst columns. Liquid propane gas (LPG) is used has the fuel for heating the system instead of electricity thereby reducing the cost of products. The received oils were also test with real engines, diesel pump and gasoline brush cutters, which are amongst the most commonly used engines in daily life. Typically previous studies on the pyrolysis of plastics have focused on the characterization of their products; solid, liquid and gas, but few literature examples have tested the resulting liquid product with real engines. In the cases that engine studies have been undertaken only simulation engine have been used and have not been tested in actual machinery. ${ }^{10,25}$ It should be noted that this work uses gasohol 91 (not gasoline 95) to comparison with pyrolysis oil. This is due to the fact gasoline 95 is costly and not widespread throughout Thailand, as such gasohol 91 is representative of a fuel utilised throughout the region.

\section{Experimental details}

Commercial grade bentonite clay (powdered form) was purchased from Thai Nippon Chemical Industry Co., Ltd. Plastic wastes used in this study were food and beverage, drinking water, liquid soap and shampoo packaging materials. These municipal wastes were collected from Environmental Conservation Organization in Khon Kaen, Thailand. Waste plastics were separated according to polymer (PS, PP, LDPE and HDPE), washed with tap water, sun-dried and cut into $1 \mathrm{~cm}^{2}$ pieces.

The thermogravimetric analysis of plastic waste samples was performed with a Shimadzu TGA-50. Typically $20 \mathrm{mg}$ samples were placed in a $4 \mathrm{~mm}$ diameter platinum pan. The thermal decomposition experiments were carried out from room temperature to $700{ }^{\circ} \mathrm{C}$ at a heating rate of $10{ }^{\circ} \mathrm{C} \min ^{-1}$. The system was constantly purged with $10 \mathrm{ml} \mathrm{min}^{-1}$ of $\mathrm{N}_{2}$ to ensure pyrolysis conditions inside the TGA furnace. For each experiment, data of weight loss $(\%)$ and temperature $\left({ }^{\circ} \mathrm{C}\right)$ were recorded.

The clay sample was characterized porosimetry by $\mathrm{N}_{2}$ adsorption-desorption isotherms at $77 \mathrm{~K}$ in ASAP 2020 Micromeritics equipment. Prior to the adsorption measurement, the sample was first degassed at $110^{\circ} \mathrm{C}$ under vacuum until pressure $<50 \mathrm{mmHg}$ to remove moisture. Brunauer-Emmet-Teller (BET) method was used for surface area measurement. Total pore volume was evaluated from the adsorbed volume of nitrogen at $P / P^{0}$ around 0.99 . Micropore volume was calculated by the Dubinin-Radushkevich (DR) method. The average pore size was deduced using BarrettJoyner-Halenda $(\mathrm{BJH})$ method. The powdered clay was then compressed by hydraulic press at 50 bar to produce catalytic pellets with a diameter of $1 \mathrm{~cm}$ and length of $1.5 \mathrm{~cm}$.

A bench scale fixed-bed pyrolysis stainless steel batch reactor (diameter $35 \mathrm{~cm}$, length $60 \mathrm{~cm}$, maximum capacity $5 \mathrm{~kg}$ ) was used for production of oil from plastic packaging wastes (Fig. 1). $1 \mathrm{~kg}$ of plastic wastes was loaded into the reactor for each pyrolysis reaction. The reactor was heated externally by liquid propane gas to the required operating temperature at heating rates of 10, 15, 20 and $25{ }^{\circ} \mathrm{C} \min ^{-1}$. Reaction was carried out at $500{ }^{\circ} \mathrm{C}$ for 10 minute under a flow of nitrogen purge gas. The pyrolysis gas was passed through catalyst column at a ratio of $0.05,0.1,0.15$ and 0.2 by weight of catalyst to plastic. The catalyst column made from glass (diameter $5 \mathrm{~cm}$, length 100) and load with catalyst in pellet form. Pellets are formed on compression of the catalyst powder with hydraulic press at pressure of 50 bar, the resulting pellet have a diameter of $1 \mathrm{~cm}$ and length of $1.5 \mathrm{~cm}$. No binder was used in the formation of the pellets. Fig. S1 in the ESI $\dagger$ demonstrates the bentonite clay, hydraulic press machine, palletization block and catalyst in pellet form. The resulting gas products were collected via water cooled condenser. The oil yield was determined based on the initial mass of plastic waste. A control experiment without catalyst was also conducted for comparison. It is important to note that the catalyst cannot be used in powder form when operating at a bench scale due to the generation of a significant pressure drop in catalyst column. As such typical literature examples that utilize catalysts in the powder form require long processing times (more than 1 hour) to pass the product gas through catalyst column and into the condenser to form the liquid product. By using the catalyst in a pellet form, the process time has been reduced to only 10 minute for pyrolysis of $1 \mathrm{~kg}$ plastic waste.

Fuel properties of the resulting pyrolysis oils were tested by the standard methods, including calorific value by bomb calorimeter, density by ASTM D1298, kinematic viscosity at $40{ }^{\circ} \mathrm{C}$ by ASTM D93, flash point by ASTM D93 and pour point by ASTM D79. The functional groups of oil were characterized by Fourier Transform Infrared spectroscopy (Bruker, Tensor 27) and the liquid fraction was analysed by Gas Chromatography Mass Spectrometry (PerkinElmer, TurboMatrix HS). The FTIR spectra of resulting oils were compare \% similar with commercial fuels by using Bruker software.

The pyrolysis oils with and without using catalyst were used to operate both diesel and gasoline engines. A four-stroke engine, single piston diesel pump (HINOTA, ELP503) with maximum speed $3000 \mathrm{rpm}$, power $2.2 \mathrm{~kW}$ and maximum flow rate $40 \mathrm{~m}^{3} \mathrm{~h}^{-1}$ was used for diesel engine tests. A four-stroke engine gasoline brush cutter (Kanto, KT-NBC-4STK), with 


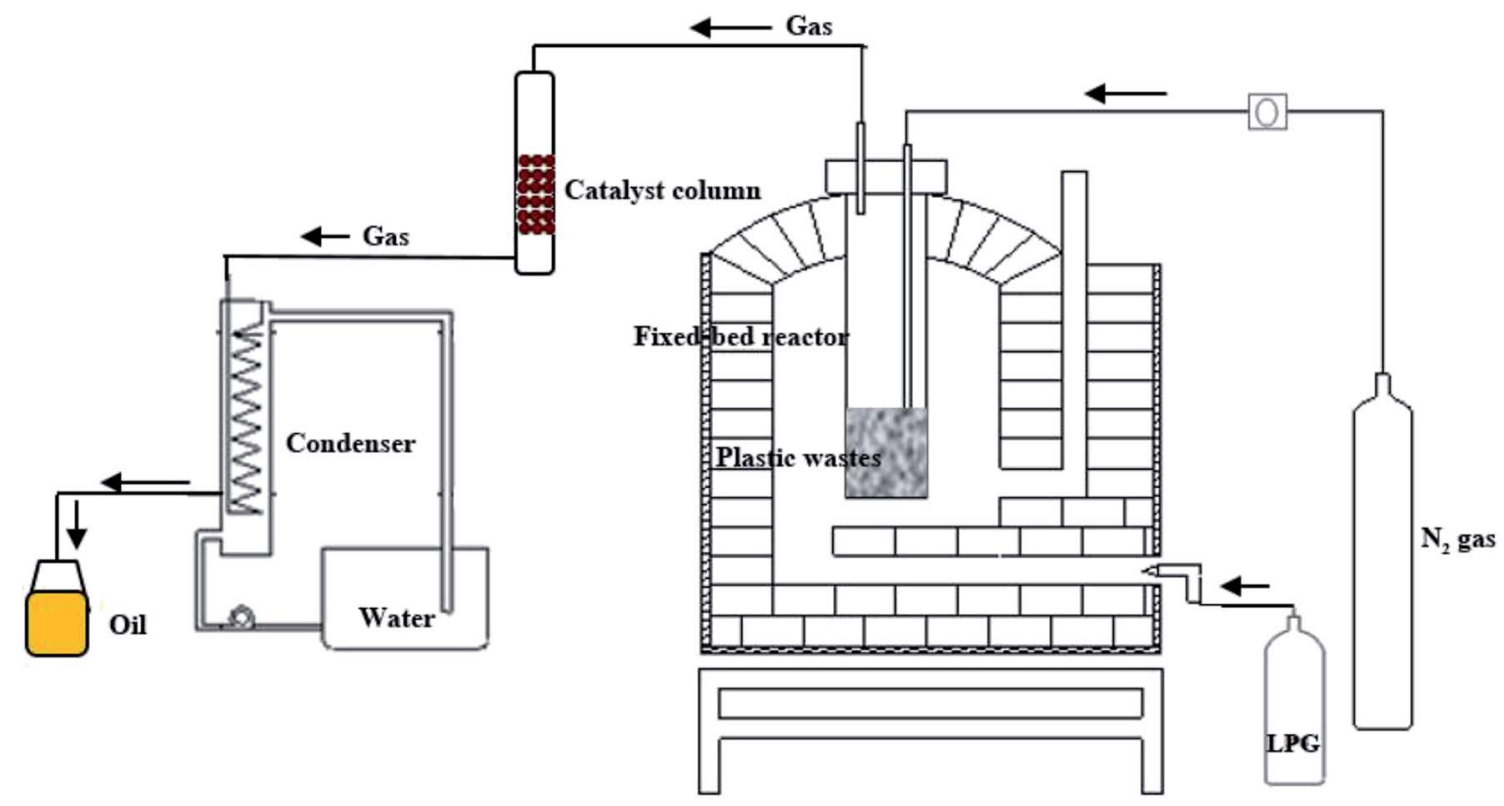

Fig. 1 Schematic diagram of bench scale pyrolysis unit.

a $6000 \mathrm{rpm}$ speed, power $2.6 \mathrm{~kW}$ and $40 \mathrm{~cm}^{3}$ displacement was used as a model petrol engine. The exhaust gas composition were analysed with an EMS 5002 gas analyser. Engine temperature was also measured by a GM700 infrared thermometer. The engine current was measured by a MX 655 multimeter and then converted to power.

\section{Results and discussion}

A bench scale fixed-bed pyrolysis batch reactor was used for production of oil from plastic packaging wastes. Fig. 1 shows the schematic diagram of plastic pyrolysis setup. Importantly, this system in combination with the use of widely available and cost effective bentonite clay catalysts, lead to the formation of no solid products or char residues remaining in the reactor at the end of the pyrolysis cycle.

\section{Raw materials and catalyst characterization}

The TG curves of each plastic waste demonstrated a similar behaviour but at different thermal decomposition temperatures, as shown in Fig. 2. The polycyclic structure of PS degraded between $250-480{ }^{\circ} \mathrm{C}$, while those plastics possessing

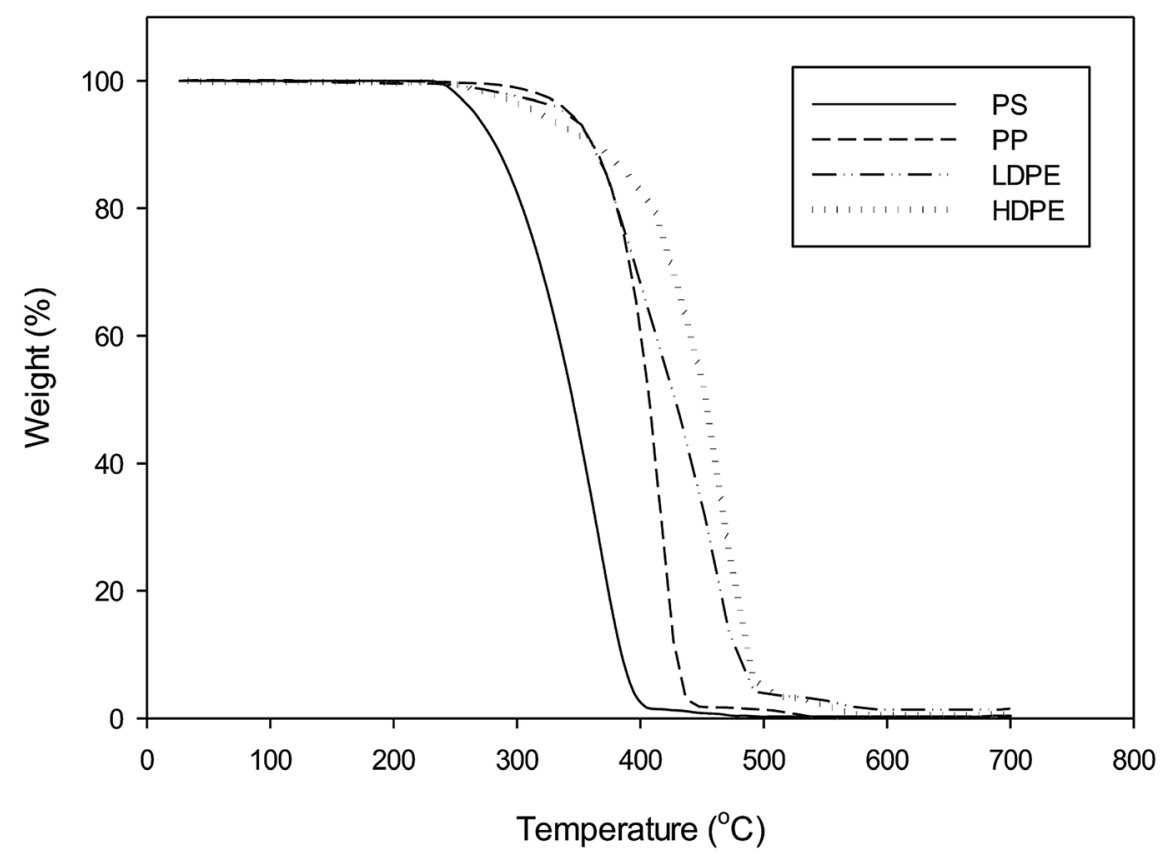

Fig. 2 TGA curves of waste plastics heated under nitrogen at $10{ }^{\circ} \mathrm{C} \mathrm{min}^{-1}$. 


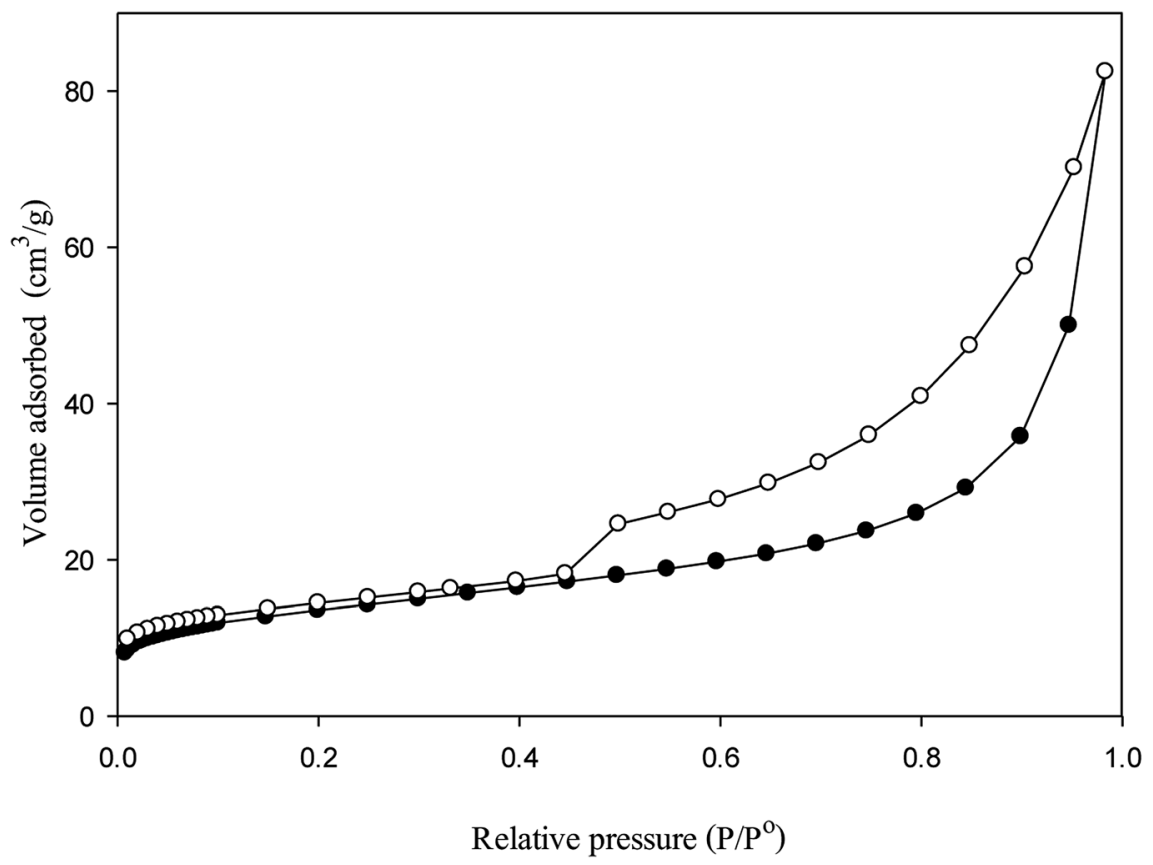

Fig. $3 \quad \mathrm{~N}_{2}$ adsorption-desorption isotherms at $77 \mathrm{~K}$ of bentonite clay.

a polyolefin structure (PP and $\mathrm{PE}$ ) degraded at higher temperatures of $280-520^{\circ} \mathrm{C}$ and $280-580^{\circ} \mathrm{C}$, respectively. These results are in agreement with previous studies in the literature. ${ }^{20,26} \mathrm{PS}$ was also reported to decompose at lower temperatures than PP, LDPE and HDPE. This mean that the pyrolysis temperature of $500{ }^{\circ} \mathrm{C}$ used in this study was suitable.

The chemical composition of bentonite clay from product specification from Thai Nippon Chemical Industry Co., Ltd was found to be $\mathrm{SiO}_{2} 46 \mathrm{wt} \%, \mathrm{Al}_{2} \mathrm{O}_{3} 17 \mathrm{wt} \%, \mathrm{Fe}_{2} \mathrm{O}_{3} 6 \mathrm{wt} \%, \mathrm{Na}_{2} \mathrm{O}$ $1.5 \mathrm{wt} \%, \mathrm{CaO} 2.5 \mathrm{wt} \%$ and $\mathrm{TiO}_{2} 0.2 \mathrm{wt} \%$. Bentonite clays have a similar composition to $\mathrm{SiO}_{2}$ and $\mathrm{Al}_{2} \mathrm{O}$ catalyst previously investigated as pyrolysis catalysts. ${ }^{6-8}$ Bentonite also had some compositional similarities to kaoline and red mud. The chemical compositions of kaoline were $\mathrm{Al}_{2} \mathrm{O}_{3} 46.07 \mathrm{wt} \%, \mathrm{SiO}_{2}$ $43.12 \mathrm{wt} \%, \mathrm{TiO}_{2} 0.74 \mathrm{wt} \%, \mathrm{CaO} 0.03 \mathrm{wt} \%$ and others while red mud had $\mathrm{Fe}_{2} \mathrm{O}_{3} 36.5 \mathrm{wt} \%, \mathrm{Al}_{2} \mathrm{O}_{3} 23.8 \mathrm{wt} \%, \mathrm{TiO}_{2} 13.5 \mathrm{wt} \%, \mathrm{SiO}_{2}$

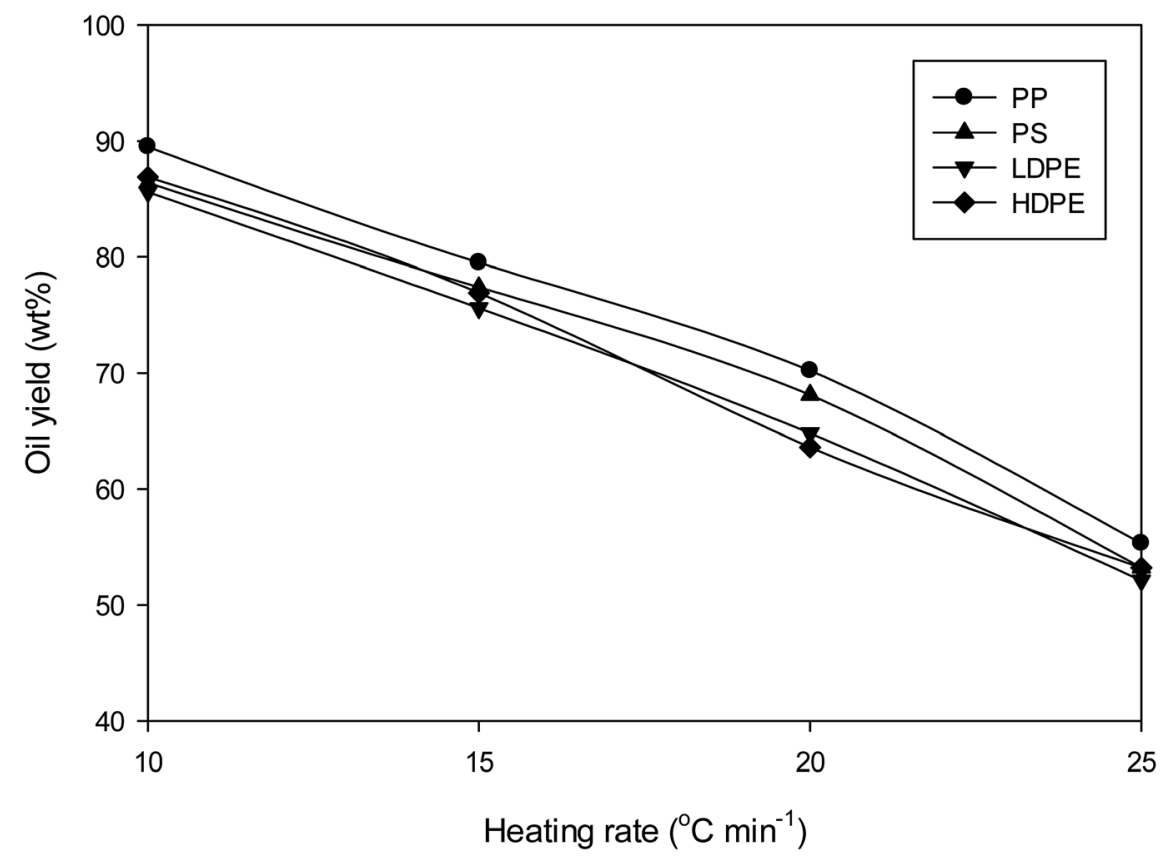

Fig. 4 Influence of heating rate on production of oil from plastic wastes. 
Table 1 Effect of catalyst on yield and fuel properties of oil

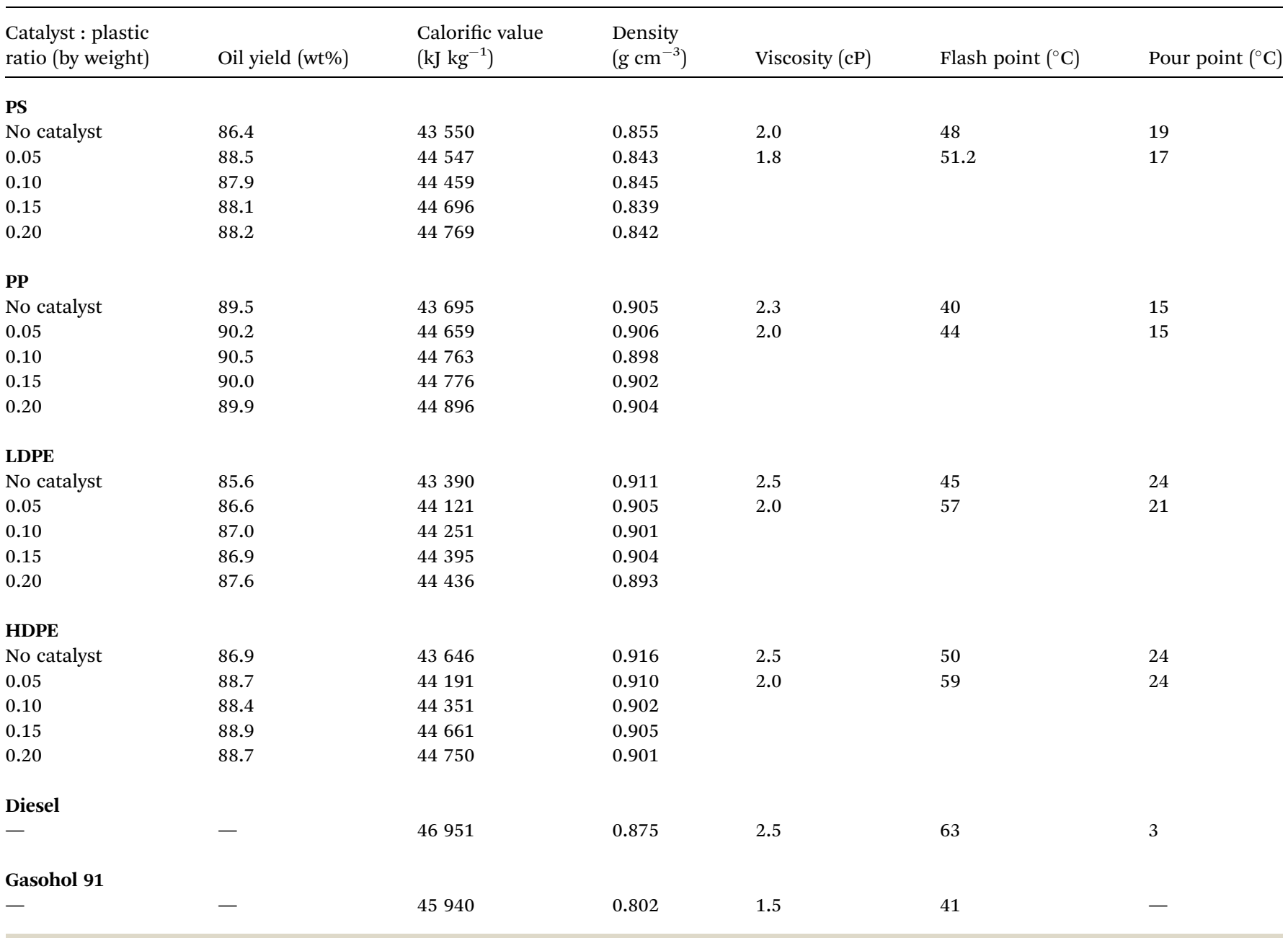

$8.5 \mathrm{wt} \%$, CaO $5.3 \mathrm{wt} \%, \mathrm{Na}_{2} \mathrm{O} 1.8 \mathrm{wt} \%$ and others. ${ }^{8,9}$ Low ratio of $\mathrm{SiO}_{2} / \mathrm{Al}_{2} \mathrm{O}_{3}$ indicated the acidity of the catalyst, thus highlighting the possible acidic nature of the bentonite catalyst.

Fig. 3 shows the $\mathrm{N}_{2}$ adsorption-desorption isotherms of the catalyst. According to the IUPAC classification, the shape of isotherm is type IV with the increasing in relative pressure, capillary condensation occurs. The hysteresis loop may be attributed to the mesoporous structure. Additionally, the steep jump observed at high relative pressure $(>0.9)$ indicates some macropore existence. ${ }^{6}$ The BET surface area of bentonite clay was found to be $47 \mathrm{~m}^{2} \mathrm{~g}^{-1}$ with total pore volume $0.13 \mathrm{~cm}^{3} \mathrm{~g}^{-1}$. The micropore volume is $0.02 \mathrm{~cm}^{3} \mathrm{~g}^{-1}$ or $15 \%$ of total pore volume. The average pore size of the material was $10.9 \mathrm{~nm}$ and thus the catalyst was highly mesoporous.

\section{Effect of pyrolysis conditions on oils properties}

To investigate the effect of heating rate of liquid pyrolysis-oil yield, plastic waste was subjected to pyrolysis without catalyst at $10-25{ }^{\circ} \mathrm{C} \mathrm{min}^{-1}$. Fig. 4 demonstrates that the pyrolysis-oil yield decreases as a heating rate increase. This highlighted that low heating rates led to secondary reactions of the solid and liquid products, primarily due longer residence times. This results in an increase in the condensable gas yield and ultimately higher yields of the liquid product. The optimum heating rate for pyrolysis of this plastic waste was determined to be $10{ }^{\circ} \mathrm{C} \mathrm{min}^{-1}$. The results for all plastics demonstrated the same trend. These results are consistent with the work of Cahyono and Styana, who demonstrated that the liquid yield from pyrolysis of LDPE plastic bag waste decreased with increasing heating rate from 5 to $15{ }^{\circ} \mathrm{C} \min ^{-1} \cdot{ }^{27}$

Pyrolysis of plastic wastes without catalyst led to a brown coloured oil for PS and yellow for PP, LDPE and HDPE. Catalytic decomposition of the plastic waste had little effect on the colour of oil. Panda and Singh ${ }^{9}$ also found that the colour of oil obtained in catalytic pyrolysis of PP using silica, alumina and kaolin were yellow.

Table 1 indicates the comparison of oil yield with and without catalyst at different catalyst ratio. Presence of catalyst slightly increased the yield of oil as compare to without catalyst at all catalyst ratio. The use of a catalyst enhanced the ability to decompose or crack the polymer, thereby increasing the condensable gas yield and ultimately more liquid product. ${ }^{8}$ The advantages of the proposed pyrolysis system re that no char or wax is formed during the process. This is attributed to the acidic nature of the bentonite catalyst, which enabled the 
Table 2 Component in liquid fraction obtained from pyrolysis of plastic wastes using GC-MS

\begin{tabular}{|c|c|c|c|c|}
\hline \multirow[b]{3}{*}{ Component } & \multicolumn{4}{|l|}{ \%Area } \\
\hline & \multicolumn{2}{|c|}{ No catalyst } & \multicolumn{2}{|l|}{ Catalyst } \\
\hline & Aromatic & Non-aromatic & Aromatic & Non-aromatic \\
\hline \multicolumn{5}{|l|}{ PS } \\
\hline $\mathrm{C}_{5}-\mathrm{C}_{9}$ & 60.22 & 0.44 & 61.80 & 1.74 \\
\hline $\mathrm{C}_{10}-\mathrm{C}_{13}$ & 1.00 & 0.00 & 1.00 & 0.43 \\
\hline $\mathrm{C}_{13}$ & 34.77 & 3.57 & 31.53 & 3.50 \\
\hline \multicolumn{5}{|l|}{ PP } \\
\hline $\mathrm{C}_{5}-\mathrm{C}_{9}$ & 6.26 & 18.65 & 10.94 & 21.45 \\
\hline $\mathrm{C}_{10}-\mathrm{C}_{13}$ & 2.20 & 7.76 & 1.44 & 15.05 \\
\hline $\mathrm{C}_{13}$ & 13.50 & 61.63 & 10.10 & 40.22 \\
\hline \multicolumn{5}{|l|}{ LDPE } \\
\hline $\mathrm{C}_{5}-\mathrm{C}_{9}$ & 3.45 & 8.49 & 3.59 & 14.05 \\
\hline $\mathrm{C}_{10}-\mathrm{C}_{13}$ & 0.00 & 19.31 & 0.00 & 22.28 \\
\hline $\mathrm{C}_{13}$ & 0.96 & 67.79 & 0.00 & 62.08 \\
\hline \multicolumn{5}{|l|}{ HDPE } \\
\hline $\mathrm{C}_{5}-\mathrm{C}_{9}$ & 2.52 & 13.79 & 3.12 & 14.72 \\
\hline $\mathrm{C}_{10}-\mathrm{C}_{13}$ & 0.00 & 21.18 & 0.00 & 21.43 \\
\hline $\mathrm{C}_{13}$ & 0.00 & 65.45 & 0.00 & 62.73 \\
\hline \multicolumn{5}{|l|}{ Diesel } \\
\hline & \multicolumn{2}{|l|}{ Aromatic } & \multicolumn{2}{|c|}{ Non-aromatic } \\
\hline $\mathrm{C}_{5}-\mathrm{C}_{9}$ & \multicolumn{2}{|l|}{2.1800} & \multicolumn{2}{|c|}{1.1500} \\
\hline $\mathrm{C}_{10}-\mathrm{C}_{13}$ & \multicolumn{2}{|l|}{0.6300} & \multicolumn{2}{|l|}{11.1700} \\
\hline $\mathrm{C}_{13}$ & \multicolumn{2}{|l|}{0.5000} & \multicolumn{2}{|l|}{84.3700} \\
\hline \multicolumn{5}{|l|}{ Gasohol 91} \\
\hline & \multicolumn{2}{|l|}{ Aromatic } & \multicolumn{2}{|c|}{ Non-aromatic } \\
\hline $\mathrm{C}_{5}-\mathrm{C}_{9}$ & \multicolumn{2}{|l|}{43.2700} & \multicolumn{2}{|c|}{50.5200} \\
\hline $\mathrm{C}_{10}-\mathrm{C}_{13}$ & \multicolumn{2}{|l|}{1.0800} & \multicolumn{2}{|l|}{5.1300} \\
\hline $\mathrm{C}_{13}$ & \multicolumn{2}{|l|}{0.0000} & \multicolumn{2}{|l|}{0.0000} \\
\hline
\end{tabular}

decomposition or cracking of waxes to lighter products. In contrast, Jan et al. used $\mathrm{CaCO}_{3}$ as catalyst for the pyrolysis of HDPE and found that wax formation occured..$^{5}$ Mastral et al. also found that wax formed when undertaking pyrolysis of HDPE with HZSM-5 zeolite as an acidic catalyst. ${ }^{6}$ The highly acidic catalyst (low $\mathrm{SiO}_{2} / \mathrm{Al}_{2} \mathrm{O}_{3}$ ratio) was more active in cracking waxes compared to the less acidic catalyst (high $\mathrm{SiO}_{2} / \mathrm{Al}_{2} \mathrm{O}_{3}$ ratio). ${ }^{28}$ For bentonite clay, the ratio of $\mathrm{SiO}_{2}: \mathrm{Al}_{2} \mathrm{O}_{3}$ was 0.94 , while HZSM-5 zeolite used in Mastral et al. ${ }^{6}$ had $\mathrm{Si}: \mathrm{Al}$ ratio of 35. The wax is typically $\mathrm{C}_{13}-\mathrm{C}_{28}$ hydrocarbons and these components significantly decreased after using the bentonite catalyst, as shown in Table 2.

After apply catalyst a liquid yield more than $87 \%$ was obtained. López et al. used ZSM-5 and red mud as catalyst for the pyrolysis of mixed plastic wastes and found that the maximum liquid yield were 56.9 and $76.2 \mathrm{wt} \%$, respectively. ${ }^{8}$ Shah et al. also found that liquid product yields were in the range $62-79 \%$ when using $\mathrm{ZnO}, \mathrm{MgO}, \mathrm{CaC}_{2}, \mathrm{SiO}_{2}, \mathrm{Al}_{2} \mathrm{O}_{3}$ and $\mathrm{SiO}_{2}-\mathrm{Al}_{2} \mathrm{O}_{3}$ as catalysts in pyrolysis of LDPE. ${ }^{4}$ The system in this current work can obtain high liquid product with small amount of catalyst (catalyst to plastic waste ratio of 0.05 ) and at short reaction times (10 min). For example, optimum conditions for pyrolysis of $\mathrm{HDPE}$ with $\mathrm{CaCO}_{3}$ are catalyst ratio of 0.2 and reaction time of $1.5 \mathrm{~h} .{ }^{5}$ Panda and Singh also used catalyst ratio of 0.33 with reaction time of $75 \mathrm{~min}$ to received highest yield of liquid product around $89.5 \mathrm{wt} \%$ by pyrolysis of PP with kaoline. ${ }^{9}$ The catalyst ratio of $0.2-0.4$ and pyrolysis time of 1-3 $\mathrm{h}$ were also used with $\mathrm{ZnO}, \mathrm{MgO}, \mathrm{CaC}_{2}, \mathrm{SiO}_{2}, \mathrm{Al}_{2} \mathrm{O}_{3}$ and $\mathrm{SiO}_{2}-\mathrm{Al}_{2} \mathrm{O}_{3}$ as catalysts for the pyrolysis of LDPE. ${ }^{4}$

The catalyst did increase calorific values of the pyrolysis-oil to levels that were comparable to commercial fuels, diesel and gasohol 91 - the mixture of $90 \%$ gasoline and $10 \%$ ethanol, which had value of 46951 and $45940 \mathrm{~kJ} \mathrm{~kg}^{-1}$, respectively. Literature values reported the calorific value of diesel to be between 43 800-48 $610 \mathrm{~kJ} \mathrm{~kg}^{-1}{ }^{10,21}$ These literature values are in good agreement with the results obtained in this work, which demonstrated calorific values of $44896 \mathrm{~kJ} \mathrm{~kg}^{-1}$ for PP with a catalyst : plastic ratio of 0.2 (by weight). The standard calorific value of commercial gasoline is reported as being $45600 \mathrm{~kJ}$ $\mathrm{kg}^{-1}$, this figure is identical to the calorific value for gasohol 91 used in this current study. ${ }^{4}$ The calorific value of oil obtained from pyrolysis of plastic in this work was comparable to other studies. Panda and Singh who used silica alumina and kaolin as catalysts for the pyrolysis of PP, found that the received oil had calorific value of 47120 and $47095 \mathrm{~kJ} \mathrm{~kg}^{-1}$, respectively. ${ }^{9}$ Shah et al. demonstrated that, after using $\mathrm{ZnO}, \mathrm{MgO}, \mathrm{CaC}_{2}, \mathrm{SiO}_{2}$, $\mathrm{Al}_{2} \mathrm{O}_{3}$ and $\mathrm{SiO}_{2}-\mathrm{Al}_{2} \mathrm{O}_{3}$ as pyrolysis catalysts for LDPE, the calorific value of oils were in the range $40500-45000 \mathrm{~kJ} \mathrm{~kg}^{-1}$. ${ }^{4}$ This value is comparable when using bentonite (44 121-44 $436 \mathrm{~kJ}$ $\mathrm{kg}^{-1}$ ). Kumar et al. who used kaolin as a catalyst for the pyrolysis of HDPE, demonstrated that the resulting oil had a calorific value of $40170 \mathrm{~kJ} \mathrm{~kg}^{-1}$, that is lower than those obtained when using a bentonite clay, as demonstrated in this work (44 191$\left.44750 \mathrm{~kJ} \mathrm{~kg}^{-1}\right){ }^{10}$ Therefore, high calorific value of the obtained oils in this study by using catalyst showed their potential as alternatives to commercial fuel.

Application of the bentonite catalyst had little significant effect on the density of pyrolysis oil did. The densities of oil from PP, LDPE and HDPE had higher than that of PS, which is close to density of diesel and gasohol 91. Abu-Hamdeh and Alnefaie indicated that the density of diesel was $0.848 \mathrm{~g} \mathrm{~cm}^{-3}$, and close to the values for pyrolysis oils reported in this current work $\left(0.875 \mathrm{~g} \mathrm{~cm}^{-3}\right) .{ }^{21}$ In contrast, to other studies that have reported pyrolysis oil densities from HDPE of up to $1.12 \mathrm{~g} \mathrm{~cm}^{-3},{ }^{29}$ the results in this current study demonstrate promise for use in liquid fuel applications $\left(0.898-0.906 \mathrm{~g} \mathrm{~cm}^{-3}\right)$.

A viscosity of $1.8 \mathrm{cP}$ was observed for pyrolysis-oil for PS when using catalyst, encouragingly this has a viscosity close to gasohol 91 (1.5 cP). The viscosity of PP, LDPE and HDPE were $2.0 \mathrm{cP}$ and close to that of diesel $(2.5 \mathrm{cP})$ (Table 1$)$. The viscosity of commercial diesel as reported in literature is in the range of $2.0-4.5 \mathrm{cP} .{ }^{29}$ In contrast to the application of bentonite clays as catalysts in this work, Chen et al. investigated the viscosity of oil from pyrolysis HDPE and reported viscosities of $2.96 \mathrm{cP}^{29}$ Previous studies on the catalytic pyrolysis of PP with silica alumina and kaolin yielded pyrolysis oils with viscosities 2.21 and $2.27 \mathrm{cP}$, respectively. ${ }^{9}$ While Kumar et al. reported that oil from catalytic of kaolin of HDPE had viscosity of $2.1 \mathrm{cP}^{10}$ These 


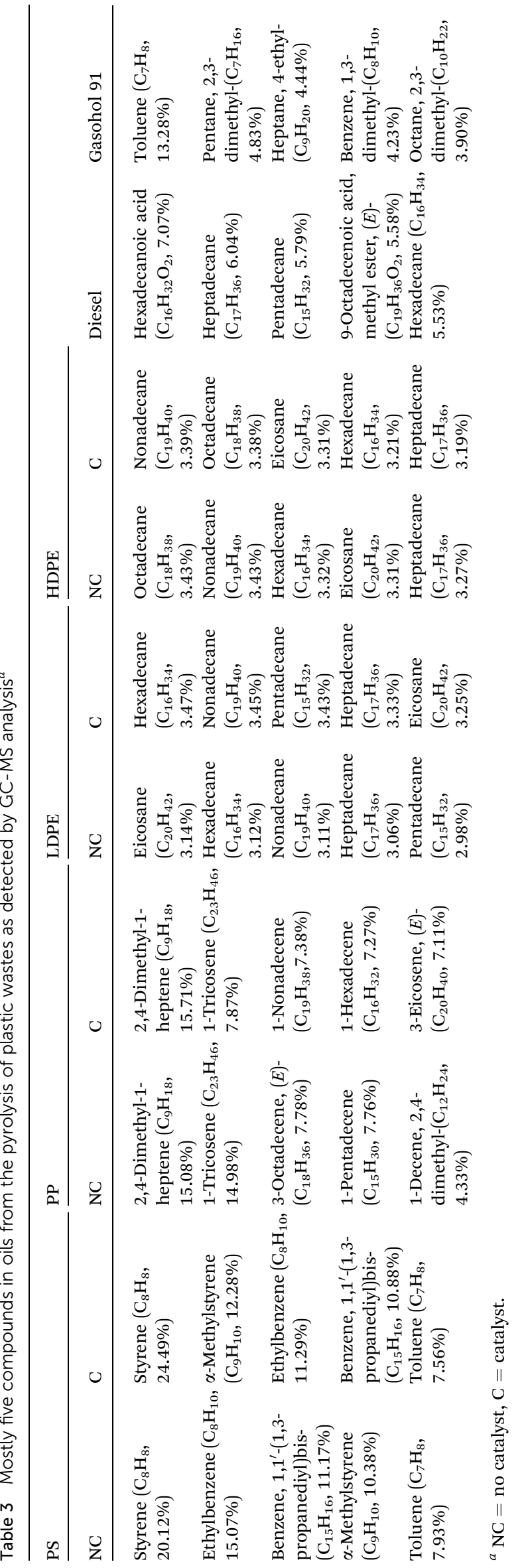

results are comparable to those obtained in this current work using bentonite clay $(2.0 \mathrm{cP})$.

The flash point of the pyrolysis-oil (liquid products) increased when processing in the presence of the clay catalyst. Pyrolysis-oils produced from LDPE and HDPE in the presence of the bentonite clay had flash points close to that of commercial diesel. In contrast, PS and PP pyrolysis-oils also produced with bentonite catalysts exhibited flash points close to gasohol 91 . The standard values of flash point for diesel and gasoline are 55-60 and $37.8-38{ }^{\circ} \mathrm{C},{ }^{4}$ respectively, which in agreement with this research. Bentonite is therefore an effective catalyst for the production of a diesel alterative from waste LDPE and HDPE. Shah et al. reported the flash point of catalytic oils when using $\mathrm{ZnO}, \mathrm{MgO}, \mathrm{CaC}_{2}, \mathrm{SiO}_{2}, \mathrm{Al}_{2} \mathrm{O}_{3}$ and $\mathrm{SiO}_{2}-\mathrm{Al}_{2} \mathrm{O}_{3}$ catalysts in the range of $30-62{ }^{\circ} \mathrm{C}^{4} \mathrm{Jan}$ et al. demonstrated the use of $\mathrm{CaCO}_{3}$ in catalytic pyrolysis of HDPE and yielded an oil with a flash point of $50{ }^{\circ} \mathrm{C} .{ }^{5}$

Comparison of the pour point of resulting oils and commercial fuels is presented in Table 1 . The pour point of gasohol 91 was not measured in this work due to the high volatility of the sample. This consistent with other research that did not measure the pour point of gasoline. ${ }^{5} \mathrm{Jan}$ et al. reported that there are no standard value of pour point for diesel and gasoline. ${ }^{5}$ The pyrolytic oils from plastic wastes had higher pour point than diesel. For all plastic wastes investigated the use of the bentonite catalyst did not significantly affect the pour point of resulting oil. However, for PS and LDPE a small decrease in the pour point values were observed on application of the bentonite clay catalysts. Pour point is known as the temperature at which the fluid stops to flow. Generally, the increase in viscosity may cause the fluid losses its flow characteristic. This is in agreement for PS and LDPE results.

Pyrolysis with no catalyst yields highly active pyrolysis-oils that can undergo polymerisation to form solid materials. Unlike pyrolysis in the absence of catalysts, the pyrolysis-oil products under catalytic conditions were low viscous liquids, indicating the enhanced breakdown and cracking of plastic wastes into low molecular weight liquid hydrocarbons. These results are supported by GC-MS data of the oils (Table 2), indicating greater proportions of lower molecular weight hydrocarbon fractions, $\mathrm{C}_{5}-\mathrm{C}_{9}$ (aliphatic and aromatic compounds) were produced using catalysts, while higher molecular weight hydrocarbon fractions, $>\mathrm{C}_{13}$, decreased. In conclude, the increasing amount of catalyst did not effect to the yield and fuel properties. Therefore, it is unnecessary to use high loadings of catalyst, leading to an optimum catalyst to plastic waste ratio of 0.05 .

The pyrolysis-oil (liquid products of pyrolysis) from plastic wastes were analysed by GC-MS (Table 2). The identified compounds were categorised according to the length of their carbon chain: $\mathrm{C}_{5}-\mathrm{C}_{9}, \mathrm{C}_{10}-\mathrm{C}_{13}$ and $>\mathrm{C}_{13}$. Those molecules with a chain length of $\mathrm{C}_{5}-\mathrm{C}_{9}$ comparable to the composition of gasoline, while $>\mathrm{C}_{13}$ are heavy oils. It was observed that catalytic and non-catalytic pyrolysis of PS mainly yielded aromatic hydrocarbons with carbon number $\mathrm{C}_{5}-\mathrm{C}_{9}$ around $60 \%$ and $>\mathrm{C}_{13}$ around $30 \%$. These compounds are similar to those present in gasohol 91 more than diesel. It has been reported that one of 

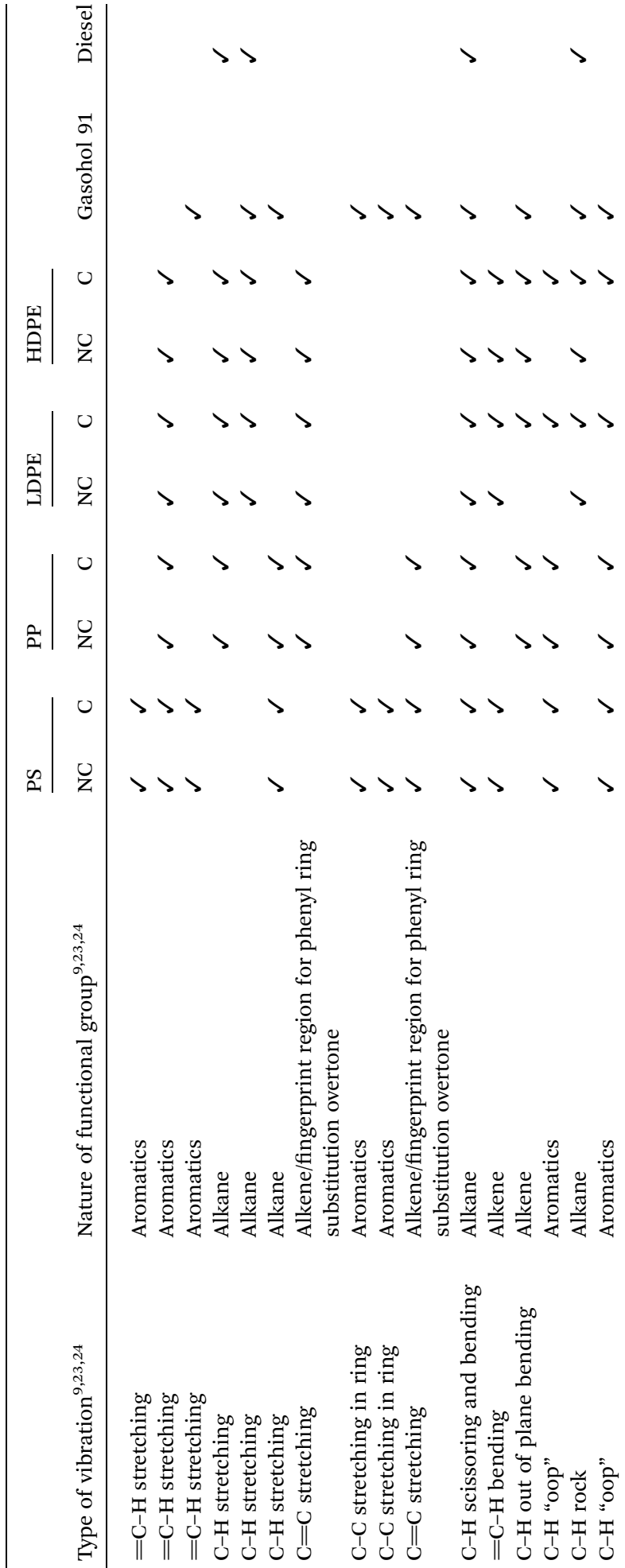

Table 5 Comparison of FTIR spectra between oil from plastic wastes and commercial fuel

\begin{tabular}{llllll}
\hline & & & \multicolumn{2}{l}{$\begin{array}{l}\text { \% Similarity with } \\
\text { gasohol 91 }\end{array}$} \\
\cline { 2 - 3 } $\begin{array}{l}\text { Type of plastic } \\
\text { waste }\end{array}$ & No catalyst & Catalyst & & No catalyst & Catalyst \\
\cline { 2 - 3 } PS & 17.90 & 20.75 & & 63.20 & 66.35 \\
PP & 86.18 & 87.63 & & 58.67 & 61.01 \\
LDPE & 96.89 & 96.08 & & 56.78 & 62.80 \\
HDPE & 96.75 & 96.53 & & 56.95 & 62.75 \\
\end{tabular}

the mechanisms of formation of aromatics during pyrolysis is via Diels-Alder reactions and subsequent dehydrogenation to form aromatic rings and it is probably related to the specific composition of the sample pyrolyzed..$^{22}$ However, in the case of polystyrene, this feedstock is highly aromatic and as such would be likely to also yield aromatic products during catalytic pyrolysis. For PP, LDPE and HDPE, the resulting oils are mostly aliphatic hydrocarbons (alkanes and alkenes) with carbon number more than $\mathrm{C}_{13}$. These results were consistent with FTIR results.

The five most abundant compounds present in the pyrolysisoils are summarized in Table 3. The pyrolysis of PS yielded, styrene $(20.12 \%)$, ethylbenzene $(15.07 \%)$, benzene, $1,1^{\prime}-(1,3-$ propanediyl)bis- (11.17\%), $\alpha$-methylstyrene $(10.38 \%)$ and toluene $(7.93 \%)$. On application of the catalyst during pyrolysis, the mainly compounds remained the same, however, in the respective ratio of these components differed. Pyrolysis of PP produced an oil containing 2,4-dimethyl-1-heptene (15.08\%), 1tricosene (14.98\%), 3-octadecene, $(E)$ - (7.78\%), 1-pentadecene (7.76\%) and 1-decene, 2,4-dimethyl- (4.33\%). Some compounds such as 1-nonadecene (7.38\%), 1-hexadecene $(7.27 \%)$ and 3eicosene, $(E)-(7.11 \%)$ appear with the use of the bentonite catalyst. For LDPE and HDPE, it was shown that pyrolysis-oils with and without catalyst had compounds like to diesel.

All compounds identified in the resulting oils are presented in Table S1 of the ESI. $\dagger$ Although the major compounds did not demonstrate a significant difference in the oils products with and without a catalyst, significant differences can be observed in the minor compounds of the two oils. Some compounds including light hydrocarbons only appear after using catalyst, while heavy hydrocarbons disappear after using catalyst (Table S1 of ESI $\dagger$ ). The oils obtained in the pyrolysis of plastic wastes under the optimum conditions of heating rate $\left(10{ }^{\circ} \mathrm{C} \mathrm{min}{ }^{-1}\right)$ and catalyst ratio $(0.05$ by weight $)$ were characterised using FTIR (Table 4 and Fig. S1 of ESI $\dagger$ ) provides the presence of different functional groups present in the oil. The FTIR spectra obtained for the pyrolysis oils with and without catalyst from PP, LDPE and HDPE are all similar, while PS significantly differs. The spectrum demonstrated $\mathrm{d}$ the presence of $=\mathrm{C}-\mathrm{H}$ stretches and consequently aromatic compounds between $3500 \mathrm{~cm}^{-1}$ and $3000 \mathrm{~cm}^{-1}$. PP, LDPE and HDPE also have dominate peaks which are between $3000 \mathrm{~cm}^{-1}$ and $2800 \mathrm{~cm}^{-1}$ showing the presence of $-\mathrm{CH}_{3},-\mathrm{CH}_{2}$ and $\mathrm{C}-\mathrm{H}$ groups. This illustrates the highly aliphatic nature of the oils products and consistence with GC-MS results. The peaks around $1600 \mathrm{~cm}^{-1}$ and $1494 \mathrm{~cm}^{-1}$ 


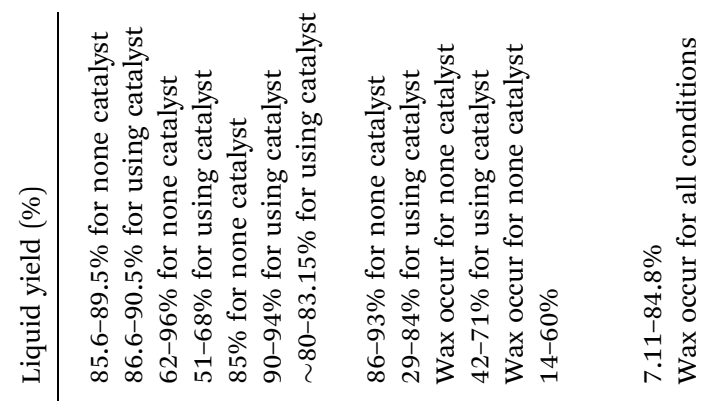

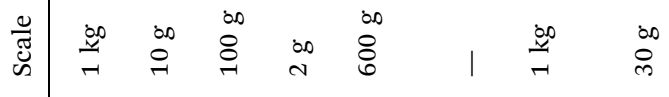

\&品寻 究

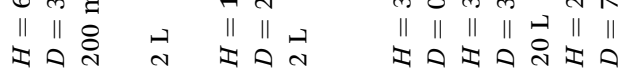
-

ㄴ.

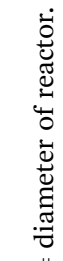

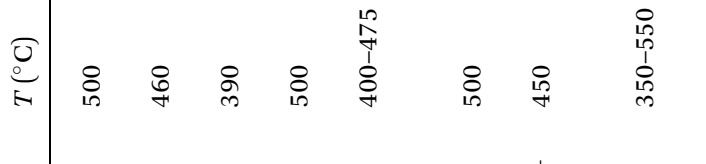

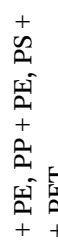

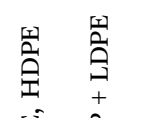

ज्ञ 

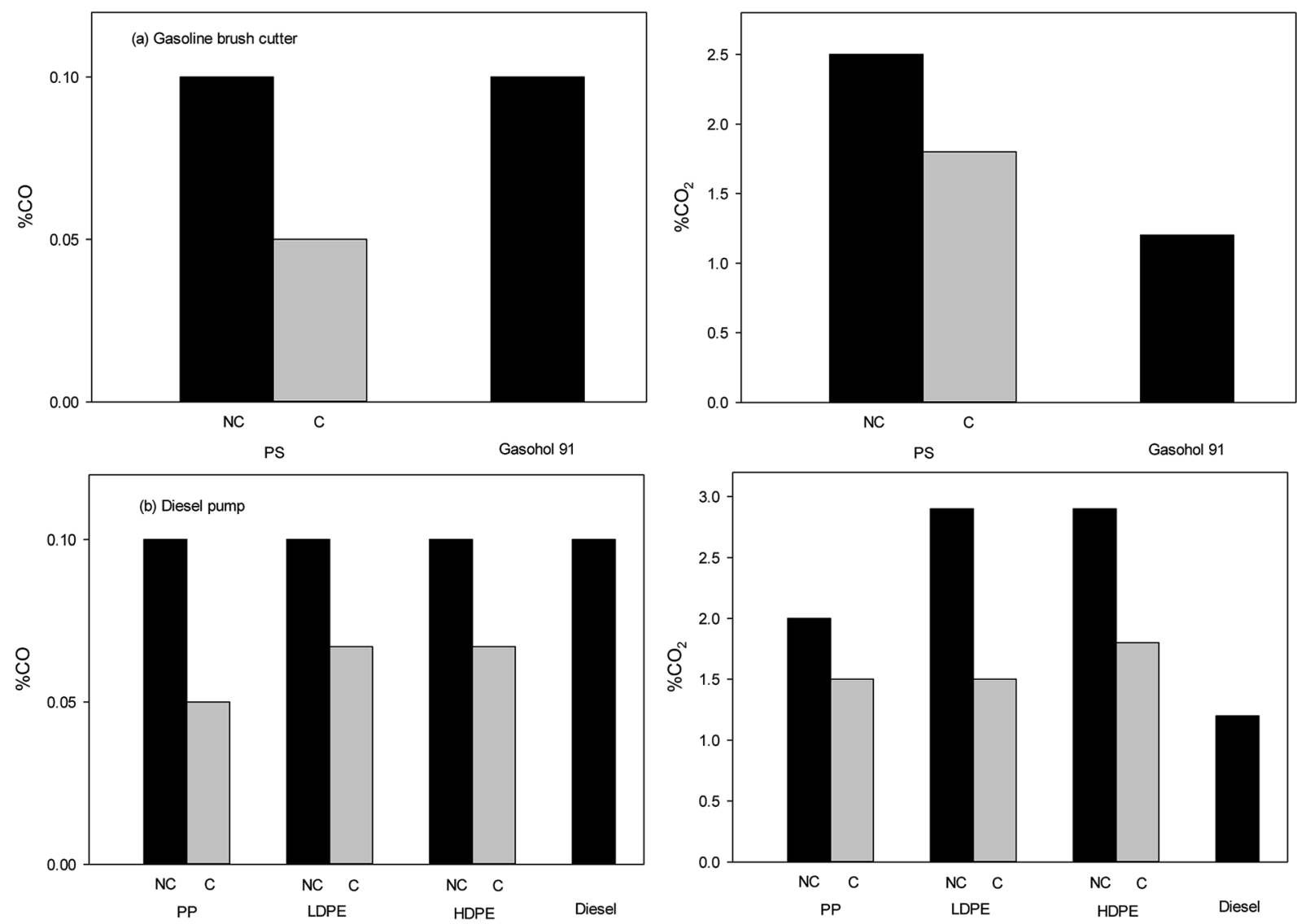

Fig. $5 \mathrm{CO}$ and $\mathrm{CO}_{2}$ emission from (a) gasoline brush cutter and (b) diesel pump at speed of $2000 \mathrm{rpm}$ (NC=no catalyst and $\mathrm{C}=$ catalyst).

that occur only for PS and gasohol 91 represent $\mathrm{C}=\mathrm{C}$ stretching in aromatic ring. The peaks around at $1456 \mathrm{~cm}^{-1}$ and $1378 \mathrm{~cm}^{-1}$ relate to alkene and alkane structure, respectively. The absorption bands at $775 \mathrm{~cm}^{-1}$ and $695 \mathrm{~cm}^{-1}$ show the presence of aromatic compounds.

When compare FTIR spectra of oils with and without catalyst with commercial fuels, it can be observed that LDPE and HDPE are similar to diesel, with more than $96 \%$ similarity match, while PP similarity was more than $86 \%$. For PS peaks, the using of catalyst increased \% similarity with gasohol 91 from 63 to 66 (Table 5).

Table 6 compares the pyrolysis conditions and \% liquid yield between this work and literature published within 5 years. With the exception of Miandad et al., ${ }^{35}$ the previously reported work on the pyrolysis of plastic was conducted on a small scale. The work conducted in this current study is one of the few examples of pyrolysis of plastic at a demonstrator scale. The pyrolysis temperature in this current work was consistent with previous studies, although the pyrolysis time was considerably shorter. This is due to the fact the pelletization of the catalyst eliminates any pressure drops that are typically associated with the use of catalysts in a powder form. Importantly, some of the literature indicated that waxes formation occurred when plastic pyrolysis took place in the absence of a catalyst. However in the current system, even in the absence of any catalyst limited wax formation was observed. This may be attributed to uniform controlled heating within the reactor and temperatures of $500{ }^{\circ} \mathrm{C}$, which may lead to greater cracking of high molecular wax product into lighter hydrocarbons. Moreover, the bentonite clay is more acidic than other catalyst, therefore results in the cracking of waxes $\left(\mathrm{C}_{13}-\mathrm{C}_{28}\right)$ into lighter hydrocarbon. Some catalyst used in literature such as $\mathrm{CaCO}_{3}$ and HZSM-5 lead to wax products. The yield of liquid product obtained from this work is comparable with those reported in the literature.

\section{Performance analysis of oil from plastic wastes with diesel and gasoline engine}

Pyrolysis-oils were tested in either a gasoline brush cutter with adjustable operating speed (1000, 2000, 3000 and $4000 \mathrm{rpm})$ or a diesel pump with a fixed speed of $2000 \mathrm{rpm}$. As discuss before, oils from the catalytic pyrolysis of PS had compounds chemical and physical properties to that of gasohol 91, while oils from PP, LDPE and HDPE oils were similar to diesel. As such, PS pyrolysis-oil was tested in the gasoline powered brush cutter and oils from PP, LDPE and HDPE test with diesel pump. It should be noted that the use of PS oils were not suitable for the diesel pump and the engine was unable to start. Similarly, when pyrolysis-oils from PP, LDPE and HDPE were used within the gasoline brush cutter, the engine was unable to operate.

The emission of carbon monoxide (CO) from engines fuelled by pyrolysis-oils and commercial fuels is shown in Fig. 5. Toxic 

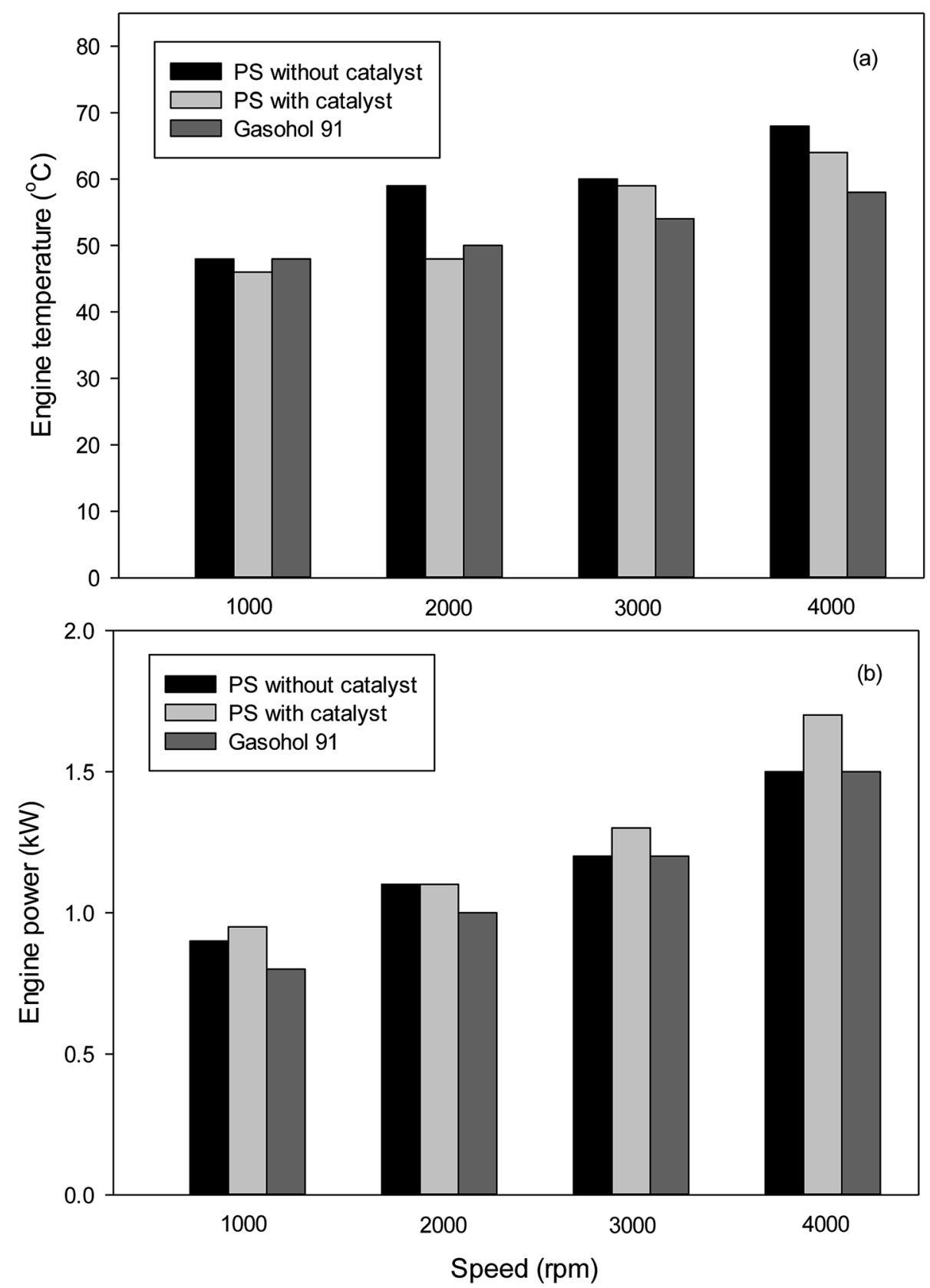

Fig. 6 Variation of engine (a) temperature and (b) power with speed for gasoline brush cutter.

CO emissions are primarily due to the lack of oxygen, poor air entrainment and incomplete combustion. It was found that pyrolysis-oils produced through the catalytic route led to a decrease in $\mathrm{CO}$ emissions as compared to commercial fuels. For diesel pump, the pyrolysis-oils from plastic wastes had CO emissions that were comparable to that of the commercial fuels for both engines. It should be noted that the maximum detection of $\mathrm{CO}$ and $\mathrm{CO}_{2}$ in the analysis system is $100 \%$ and importantly no fuels exceeded $0.1 \%$ emissions of CO. All experiments were repeat 3 times and results were found to be highly reproducible.

Fig. 5 also illustrates the carbon dioxide $\left(\mathrm{CO}_{2}\right)$ emission for both engines. The results show that $\mathrm{CO}_{2}$ emissions from pyrolysis-oils of plastic wastes were higher than commercial fuels for both engines. However, the use of bentonite clay as a catalyst can significantly decrease the $\mathrm{CO}_{2}$ emission as compared to the uncatalysed product. It should be noted that both engines produced NOx in very low amounts and below the limits of detection for the system.

Fig. 6 shows the variation of the engine temperature with speed for gasoline brush cutter. At all speeds, the use of plastic pyrolytic oil slightly increases the engine temperature. However, the using of bentonite as catalyst was able to reduce the engine temperature significantly. The use of pyrolytic oil trended to increase engine power at low speed as shown in Fig. 6. 
Moreover, the application of the clay catalyst increases the engine power to greater than that of the commercial fuel for all speed.

The engine temperatures of the diesel pump when using non-catalysed and catalysed pyrolysis-oils of plastic wastes are shown in Fig. 7. It can be observed that the using oils from the pyrolysis of plastic wastes increase the engine temperature when compare with commercial fuel. Addition of bentonite catalyst in pyrolysis process can decrease the engine temperature for all type of plastic wastes. Fig. 7 also shows the comparison of the engine power from produced oils with diesel.
It was found that waste plastic oils have comparable engine power to that of commercial diesel.

\section{Practical implications of this study}

Several key results, challenges and recommendation for future have been observed through this larger scale study. Importantly, the design of a process for larger scale commercial production is still challenging. Almost all research into the pyrolysis of plastics currently being reported in the literature is being conducted on a lab scale. Important aspects of a process including pressure drops in a system can insignificant or easily be overlooked on a small scale. However, such problems can be costly
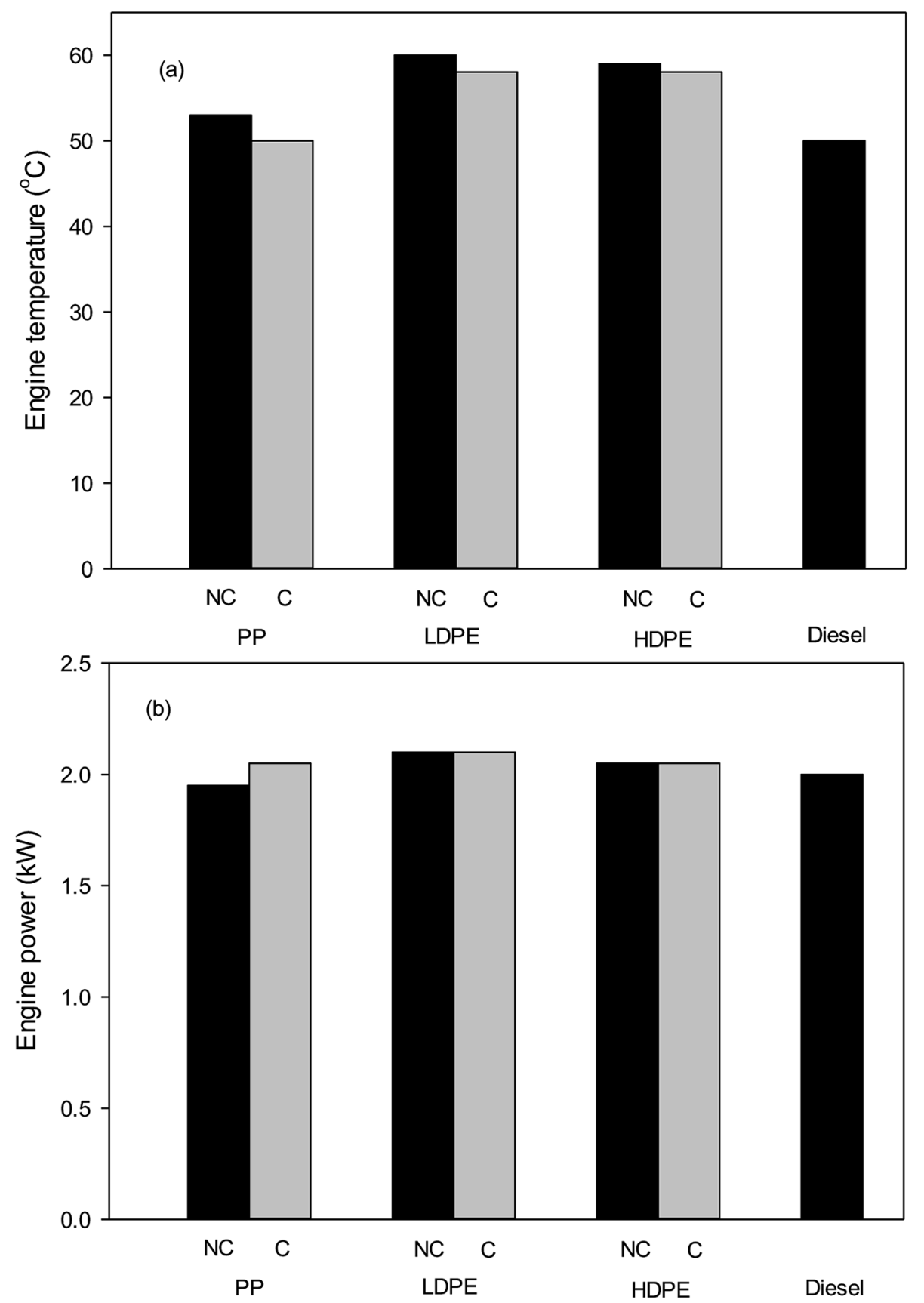

Fig. 7 (a) Engine temperature and (b) power of diesel pump at speed of 2000 rpm (NC = no catalyst and C = catalyst). 
and time consuming to correct when scaling up such processes. Therefore, such as undertaken in this current study, significant work must be conducted small pilot scale (1-50 kg). The study in bigger scale pyrolysis units, also leads to better simulations for the process parameters at a plant scale. Such results are vital for realizing the potential of such a technology for targeting the plastic problem worldwide. One challenge that is still to address is the move to a large scale continuous pyrolysis process for the conversion of plastic to fuels. The benefit of continuous process is uninterrupted production of pyrolysis oil.

Importantly, few studies have reported the use or testing of the resulting pyrolysis oil in real engine test such as motorbike. When engine tests are conducted, these are almost always carried out in simulation engine such as DI engine. This current tested the pyrolysis oil as a fuel for a diesel pump and a gasoline powered brush cutter. For widespread use and uptake end users must have confidence that performance of the pyrolysis oil fuel will be equal or better than the current gasoline/diesel on the market and should not adversely affect the lifetime of the machinery. Therefore further testing on real engines not only helps to increase consumer confidence but can also provide crucial data on the performance of the fuel. It is recommended that economic assessment of processes at a pilot scale will help promote the development of such technologies for fuel production. Significant research focusses on the use of electricity (electric furnaces) to carry out pyrolysis of the raw materials, while this current study uses LPG. The economic assessment and efficiency comparison of these two approached would aid in evaluating the best route for production at a commercial scale.

In all cases catalyst reuse should be considered. A significant different between this work and previous studies in literature is the fact that the catalyst column is separate from the pyrolysis reactor. Typically the catalyst is used within pyrolysis reactor, thus leading to changes in catalyst structure through continual direct heating at pyrolysis temperatures. By implementing a separate catalyst column it may be possible to extend the catalysts lifetime. Catalyst reuse was attempted, it was demonstrated, that the received oil had identical yields and properties to those oils synthesized with fresh catalyst. Further testing is needed to truly assess the lifetime of such catalysts in pyrolysis processes.

This study clearly demonstrates the potential for making liquid fuels from waste plastic resources. The development of such technologies should be included in the national policies of growing nations and those that currently do not possess the necessary infrastructure to collect, separate and recycle plastic waste. The large scale application of pyrolysis technologies could be a viable solution for dealing with the growing problem of plastic waste worldwide and in a cost effective manner. The utilization of waste products such as plastic for energy generation would also go some way towards also meeting the increasing need for liquid fuels. Such technologies are still reliant on having effective collection systems to supply a constant stream of plastic waste. Governments should therefore encourage specific collection schemes order to meet the needs of such facilities, in addition to developing these technologies at scale. On an international basis, pyrolysis of plastic waste should be considered as a viable option for dealing with the growing volumes of plastic waste. However, it is vital that we not only solve this short term problem of plastic wastes but also in the longer term we must move towards the development of sustainable biobased plastics and fuels as part of a circular economy.

\section{Conclusions}

The application of bentonite clay as pelletized catalyst in pyrolysis of plastic wastes, PS, PP, LDPE and HDPE has been successfully achieved. After pyrolysis with bentonite, the calorific value of liquid oils higher than thermal experiments. The GC-MS and FTIR results showed that the oils from PS had mainly aromatic hydrocarbons in gasoline range $\left(\mathrm{C}_{5}-\mathrm{C}_{9}\right)$, while PP, LDPE and HDPE had longer aliphatic hydrocarbons making them suitable for use in diesel engines. Importantly, the use of catalyst pellets eliminated the pressure drop and reducing pyrolysis processing time to only 10 minute for $1 \mathrm{~kg}$ plastic wastes. No wax formation was observed when using the bentonite clay pellets as a catalyst in the pyrolysis process, this was attributed to the high acidity of the catalyst (low $\mathrm{SiO}_{2}$ $: \mathrm{Al}_{2} \mathrm{O}_{3}$ ratio) of bentonite, thus making it more active in cracking waxes compared to the less acidic heterogeneous catalysts previously reported in the literature. The emissions and performance features of diesel and gasoline engines with pyrolysis-oils were also investigated. In terms of emissions, the using of bentonite as catalyst for pyrolysis of PS resulted in lower carbon monoxide (CO) and carbon dioxide $\left(\mathrm{CO}_{2}\right)$ for gasoline engine. Catalytic oil produced from PS resulted in higher gasoline engine power, while catalytic oils from PP, LDPE and HDPE demonstrated similar values when compare with commercial fuels. For both systems the engine temperature did not significantly differ from commercial fuels when using the catalytic pyrolysis oils. Based on these results, it can be conclude that bentonite could be effective catalyst in a pelletized form for pyrolysis of plastic and may open doors to the production of liquid fuels from wastes.

\section{Conflicts of interest}

There are no conflicts of interest to declare.

\section{Acknowledgements}

The authors acknowledge the Faculty of Engineering, Khon Kaen University for financial support in this project. The authors would also like to thank the Khon Kaen University conference travel fund for their continued support.

\section{References}

1 A. K. Awasthi, M. Shivashankar and S. Majumder, IOP Conf. Ser.: Mater. Sci. Eng., 2017, 263, 022024.

2 A. Fivga and I. Dimitriou, Energy, 2018, 149, 865. 
3 S. D. A. Sharuddin, W. M. A. W. Daud and M. K. Aroua, Energy Convers. Manage., 2016, 115, 308.

4 J. Shah, M. R. Jan, F. Mabood and F. Jabeen, Energy Convers. Manage., 2010, 51, 2791.

5 M. R. Jan, J. Shah and H. Gulab, Fuel, 2013, 105, 595.

6 J. F. Mastral, C. Berrueco, M. Gea and J. Ceamanos, Polym. Degrad. Stab., 2006, 91, 3330.

7 N. Miskolczi, A. Angyal, L. Bartha and I. Valkai, Fuel Process. Technol., 2009, 90, 1032.

8 A. López, I. de Marco, B. M. Caballero, M. F. Laresgoiti, A. Adrados and A. Aranzabal, Appl. Catal., B, 2011, 104, 211.

9 A. K. Panda and R. K. Singh, J. Fuel Chem. Technol., 2011, 39, 198.

10 S. Kumar, R. Prakash, S. Murugan and R. K. Singh, Energy Convers. Manage., 2013, 74, 323.

11 A. Adrados, I. de Marco, B. M. Caballero, A. López, M. F. Laresgoiti and A. Torres, Waste Manag., 2012, 32, 826.

12 M. V. Singh, S. Kumar and M. Sarkerb, Sustainable Energy Fuels, 2018, 2, 1057.

13 K.-H. Lee, N.-S. Noh, D.-H. Shin and Y. Seo, Polym. Degrad. Stab., 2002, 78, 539.

14 M. S. Abbas-Abadi, M. N. Haghighi, H. Yeganehb and A. G. McDonald, J. Anal. Appl. Pyrolysis, 2014, 109, 272.

15 N. K. Sundararajan and A. R. Bhagavathi, Energy Fuels, 2016, 30, 5379.

16 R. Farshi, R. Ravishankar and M. A. L. A. Raj, Res. J. Chem. Environ., 2016, 4, 52.

17 K. T. Kyaw and C. S. S. Hmwe, International Journal of Advanced Engineering and Technology, 2015, 8, 794.

18 B. Parasuram, S. Karthikeyan and S. Sungram, J. Environ. Nanotechnol., 2013, 2, 97.

19 B. Y. Arunkumar and C. N. Nataraj, Int. J. Res. Eng. Adv. Technol., 2017, 4, 114.

20 K. H. Lee and D. H. Shin, Waste Manag., 2006, 27, 168.
21 N. H. Abu-Hamdeh and K. A. Alnefaie, Fuel, 2015, 150, 318. 22 A. López, I. de Marco, B. M. Caballero, M. F. Laresgoiti and

A. Adrados, Waste Manag., 2010, 30, 620.

23 R. Miandad, M. A. Barakat, A. S. Aburiazaiza, M. Rehan, I. M. I. Ismail and A. S. Nizami, Int. Biodeterior. Biodegrad., 2017, 119, 239.

24 M. Rehan, R. Miandad, M. A. Barakat, I. M. I. Ismail, T. Almeelbi, J. Gardy, A. Hassanpour, M. Z. Khan, A. Demirbas and A. S. Nizami, Int. Biodeterior. Biodegrad., 2017, 119, 162.

25 I. Kalargaris, G. Tian and S. Gu, Energy, 2017, 131, 179.

26 L. S. Silvarrey and A. N. Phan, Int. J. Hydrogen Energy, 2016, 41, 16352.

27 M. S. Cahyono and U. I. F. Styana, Conserve: Journal of Energy and Environmental Studies, 2017, 1(1), 1.

28 S. D. A. Sharuddin, F. Abnisa, W. M. A. W. Daud and M. K. Aroua, Energy Convers. Manage., 2016, 115, 308.

29 W. Chen, S. Shi, J. Zhang, M. Chen and X. Zhou, Energy Convers. Manage., 2016, 112, 41.

30 A. F. Anene, S. B. Fredriksen, K. A. Saetre and L.-A. Tokheim, Sustainability, 2018, 10, 3979.

31 M. V. Singh, S. Kumar and M. Sarker, Sustainable Energy Fuels, 2018, 2, 1057.

32 D. K. Ratnasari, M. A. Nahil and P. T. Williams, J. Anal. Appl. Pyrolysis, 2017, 124, 631.

33 B. Kunwar, B. R. Moser, S. R. Chandrasekaran, N. Rajagopalan and B. K. Sharma, Energy, 2016, 111, 884.

34 L. C. Lerici, M. S. Renzini and L. B. Pierella, Procedia Mater. Sci., 2015, 8, 297.

35 R. Miandad, M. A. Barakat, M. Rehan, A. S. Aburiazaiza, I. M. I. Ismail and A. S. Nizami, Waste Manag., 2017, 69, 66.

36 N. A. Abdullah, A. Novianti, I. I. Hakim, N. Putra and R. Koestoer, IOP Conference Series: Earth and Environmental Science, 2018, 105, 012033. 